\title{
Uterine Cavity Assessment Prior to ICSI in Patients with Reproductive Failure: 3 Dimensional Gel Instillation Sonohysterography VS. Office Hysteroscopy
}

\author{
Abd El Naser Abd El Gaber Ali ${ }^{1}$, Ahmed Ali M. Nasr ${ }^{2 *}$, Hazem H. Ahmed ${ }^{1}$, Mostafa M. \\ Khodry $^{1}$, Mahmoud I. El- Rasheedy ${ }^{2}$ \\ ${ }^{1}$ Obstetrics \& Gynecology Department - Faculty of Medicine- South Valley University, Egypt \\ ${ }^{2}$ Obstetrics \& Gynecology Department - Faculty of Medicine- Al-Azhar University, Egypt
}

"Corresponding Author: Ahmed Ali M. Nasr, Obstetrics \& Gynecology Department - Faculty of Medicine-Al-Azhar Universities, Egypt, Email: Aam_Nasr@yahoo.com

\begin{abstract}
Objective: To compare 3D Gel installation sonohysterography (3D GIS) with office hysteroscopy (OH) in assessment of uterine cavity prior to ICSI procedure in patients with reproductive failure

Patients and Methods: 180 women with reproductive failure (infertility or repeated pregnancy losses) planned for ICSI procedure were recruited from those attendants of outpatient infertility clinic of obstetrics and gynecology department of Qena and Al-Azhar University Hospitals during the period from January 2016 to December 2016. Uterine cavity assessment was done by $3 \mathrm{D} \mathrm{Gel} \mathrm{installation} \mathrm{sonohysterography} \mathrm{and}$ office hysteroscopy in the postmenstrual proliferative phase of menstrual cycle. Sensitivity and specificity, positive and negative predictive values of $3 \mathrm{D}$ Gel instillation sonohysterography were assessed.
\end{abstract}

Results: 27 cases (15\%) had abnormal uterine cavity or intrauterine lesions and 153 cases (85\%) reported as normal by 3 D GIS (sensitivity of $88.9 \%$, specificity $98 \%$, positive predictive value of $88.9 \%$ and negative predictive value $98 \%$ ).

Conclusions: $3 D$ GIS had good predictive values in detection of uterine cavity anomalies and intrauterine lesions in comparison to hysteroscopy.

Recommendations: 3D GIS can be an alternative to office hysteroscopy in uterine cavity assessment prior to ICSI procedure.

Keywords: 3D Gel Installation Sonohysterography-Office Hysteroscopy - ICSI.

\section{INTRODUCTION}

In fact, infertility related to uterine cavity abnormalities has been estimated to be the causal factor in as many as $10 \%$ to $15 \%$ of couples seeking treatment. Moreover, abnormal uterine findings have been found in $34 \%$ to $62 \%$ of infertile women [1]. A successful pregnancy outcome for infertile women undergoing ICSI procedure depends on many factors. Among these factors good embryo quality (A or B), favorable intrauterine environment and a skillful ICSI laboratory are prerequisites to achieve a successful pregnancy outcome. Intrauterine abnormalities play an important role in implantation failure in ICSI trials [2, 3, and 4].

Different methods such as hysterosalpingography ARC Journal of Gynecology and Obstetrics
(HSG), transvaginal sonography (TVS), three dimensional transvaginal sonography (3-D TVS), three dimensional saline infusion sonography (3-D SIS) and diagnostic hysteroscopy, can be used in uterine abnormalities diagnosis. Hysteroscopy has been established as gold standard in infertility work up with high accuracy in diagnosis $[3,5,6]$. The availability of office hysteroscopy nowadays has been used for outpatients as a routine examination. It allows direct visualization of the uterine cavity and detects any uterine cavity abnormalities as biconuate uterus, uniconuate or uterine septum, also can detect the presence of intrauterine lesions or pathologies such as polyps, submucous fibroids or adhesions [7].

Recently transvaginal 3D ultrasonography is considered as accurate and noninvasive tool for 
uterine cavity assessment in outpatients so it can take place.

Office hysteroscopy (OH) costs less in comparison to hysteroscopy with no complications [9, 10]. Instillation sonography was introduced to improve the reliability of transvaginal ultrasound and, in the meantime, make advantage of its relative easiness compared to Diagnostic Hysteroscopy [11]. Sonohysterography is a procedure in which fluid (saline or gel) is instilled transcervically into the uterine cavity to provide enhanced visualization of the endometrial lining during transvaginal ultrasound examination. Both saline infusion sonohysterography and Gel Infusion sonohysterography are simple, safe, well tolerated and accurate techniques in the assessment of intra-uterine abnormalities [12]. As water easily leaks from the body cavity, it has to be replenished continuously during imaging, gel rather than watery contrast is used for GIS, which is a simple technique offering an optimal and stable distension of the uterine cavity with minimal inconvenience for the patient [15].

\section{OBJECTIVE}

The aim of this study was to evaluate 3D GIS vs. $\mathrm{OH}$ in uterine cavity assessment prior to ICSI procedure in patients with reproductive failure.

Patients and Methods: 180 women with reproductive failure planned for ICSI procedure were recruited in this study from those attendants of outpatient infertility clinic of obstetrics and gynecology department of Qena and $\mathrm{Al}$ - Azhar University Hospitals during the period from January 2016 to December 2016. Exclusion criteria was acute or chronic PID, possible pregnancy, cervical stenosis, active uterine bleeding, uterine size $>12 \mathrm{~cm}$ ).

A written consent was obtained from all participants and the study was approved from Medical Ethics Committee of Faculty of Medicine, South Valley and Al- Azhar Universities.

\section{METHOdS}

- Thorough history was taken, general and local examination was done for all participants in this study.

- For all participants uterine cavity was

ARC Journal of Gynecology and Obstetrics assessed by 3D Gel instillation sonohysterography and office hysteroscopy in the postmenstrual proliferative phase of menstrual cycle 3 or 4 days apart by 2 different operators and the findings were recorded separately. Prophylactically broad spectrum antibiotic was given to all patients to minimize intrauterine infection also intravenous or intramuscular potent analgesia was given before procedure for all patients to abolish uterine distention pain of GIS or $\mathrm{OH}$.

\section{TeChNiQue}

After inspection of the uterine cervix with the use of a Cusco's speculum, a neonatal suction tube was used for Gel Instillation connected to the syringe with gel, the use of a tenaculum for gentle cervical traction was necessary. After removal of the speculum, the $3 \mathrm{D}$ ultrasound transducer was introduced into the vagina and the uterus was determined in the longitudinal plane figure (1).

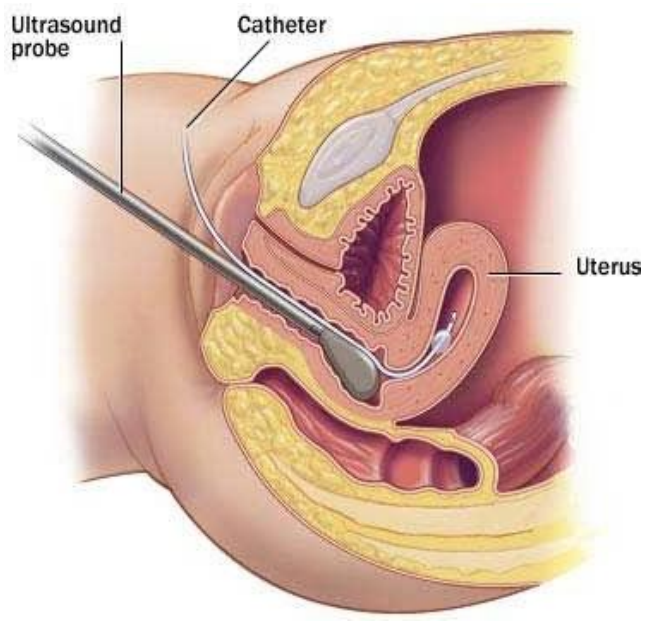

Figure1. Technique of $3 D$ GIS

Approximately $20 \mathrm{ml}$ of EX -EM gel was instilled into the uterine cavity by pushing the plunger of the syringe with light pressure by an assistant. After detection the gel foam in the uterine cavity in the sagittal plane, the transducer was rotated to the cross sectional plane to visualize uterine cavity in coronal section for better assessment. Uterine cavity contour was inspected for irregularities and suspected intracavitary lesions. Deformations of the endometrial lining, absence of central hyperechoic line, and the appearance of any structure with or without well-defined margins or variable echogenicity were considered abnormal figure $(2,3$, and 4$)$. 


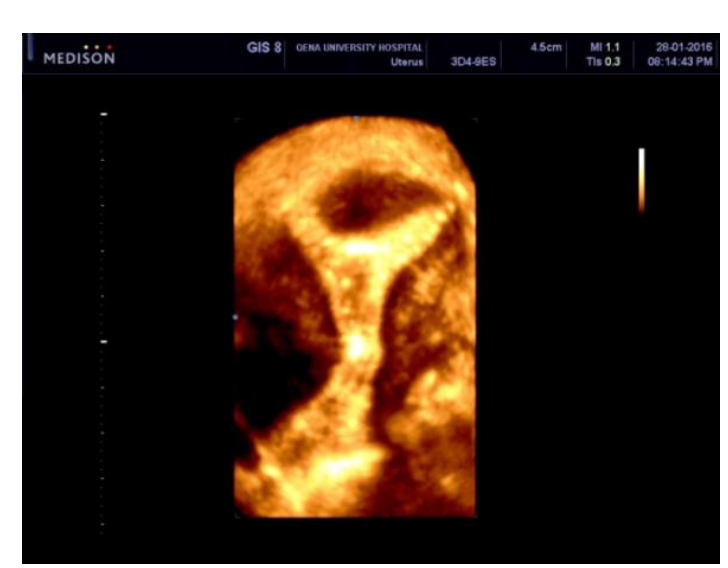

Figure2. 3D GIS shows septate uterus

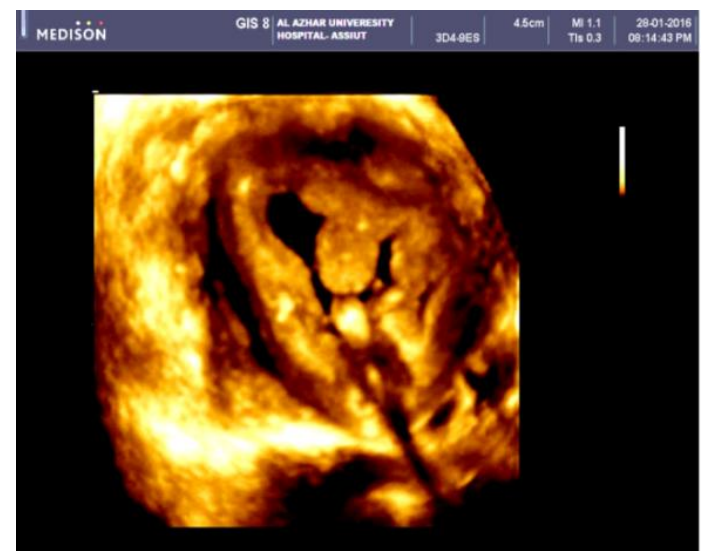

Figure3. 3D GIS shows sub mucous fibroid polyp

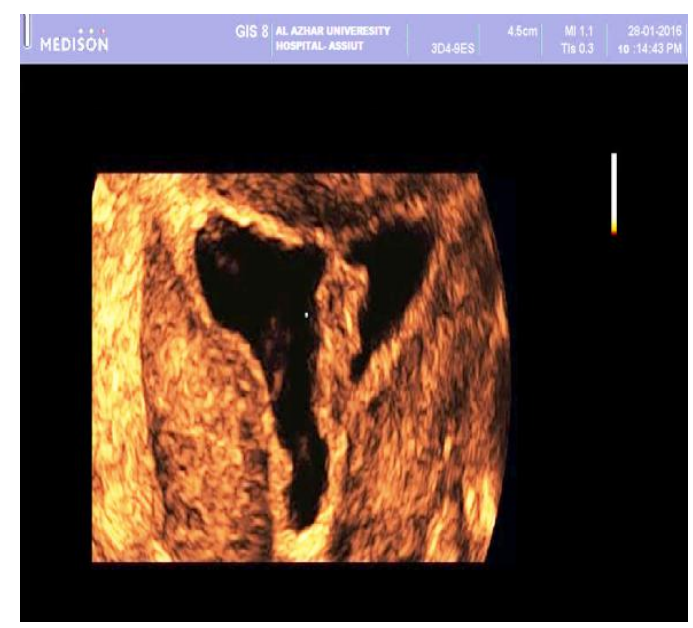

Figure4. 3D GIS shows intrauterine synechia

Office hysteroscopy was performed with a rigid micro- hysteroscope (storz trade) with a $2.9 \mathrm{~mm}$ diagnostic sheath. Normal saline solution was used as distention medium with maximum intrauterine pressure of $100 \mathrm{~mm} \mathrm{Hg}$. The uterine cavity was evaluated with inspection of both tubal ostia. Cervical preparation was done using 200 ug of misoprostol 6 hours prior to office hysteroscopy to minimize introduction failure rate. Vaginoscopy was the main trend used for office hysteroscopy. Assessment of anterior, posterior and lateral walls of uterine cavity was carefully done and any intrauterine abnormalities as uterine septum or intrauterine lesions as polyps, adhesions and sub mucous fibroids were recorded. During both procedures the patients were asked to rate the pain experienced using a $100-\mathrm{mm}$ visual analog scale (VAS).

Sensitivity, specificity, positive and negative predictive values of 3D GIS in detection of uterine anomalies or intra cavitery lesions were assessed and data interpreted and statistically analyzed.

\section{Statistical MethodS}

Results were expressed as means \pm standard deviation (SD) or number (\%). Comparison between categorical data was performed using Chi square test. Standard diagnostic indices including sensitivity, specificity, positive predictive value (PPV), negative predictive value (NPV) and diagnostic accuracy were calculated as described by Galen (1980). The data were considered significant if $p$-values was $\leq 0.05$ and highly significant if $\mathrm{p}<0.01$. Statistical analysis was performed with the aid of the SPSS computer program (version 19 windows).

\section{RESUltS}

27 of 180 cases had abnormal uterine cavity or intrauterine lesions that represents $(15 \%)$ and $153(85 \%)$ cases reported as normal by 3 D GIS, with office hysteroscopy only 24 of 27 of abnormal 3 D GIS cases confirmed as abnormal (true positive) and 3 cases were normal (false positive) and 150 of 153 of 3 D GIS normal cases were normal by office hysteroscopy (true negative and 3 cases were abnormal (false negative).

Table 1 shows characteristics of the studied patients

Table1. Patients' characteristics

\begin{tabular}{|c|c|}
\hline & NO (\%) \\
\hline \multicolumn{2}{|l|}{ Age (years) } \\
\hline$<25$ & $45(25.0)$ \\
\hline $25-30$ & $59(32.8)$ \\
\hline$\geq 30$ & $76(42.2)$ \\
\hline Mean \pm SD & $28.98 \pm 5.06$ \\
\hline \multicolumn{2}{|l|}{ BMI $\left(\mathrm{kg} / \mathrm{m}^{2}\right)$} \\
\hline$<25$ & $51(28.3)$ \\
\hline$\geq 25$ & $129(71.7)$ \\
\hline Mean \pm SD & $25.85 \pm 1.90$ \\
\hline \multicolumn{2}{|l|}{ Patient complaint } \\
\hline 1ry infertility & $109(60.5)$ \\
\hline 2ry infertility & $57(31.7)$ \\
\hline Recurrent abortion & $14(7.8)$ \\
\hline
\end{tabular}


Uterine Cavity Assessment Prior to ICSI in Patients with Reproductive Failure: 3 Dimensional Gel Instillation Sonohysterography VS. Office Hysteroscopy

Table 2 and 3 show comparison between the two procedures as regard to pain and complications respectively. Pain, bleeding and headache were significantly higher after $\mathrm{OH}$.

Table2. Pain score according to visual analog scale (VAS) during 3 D GIS and O.H

\begin{tabular}{|c|c|c|c|}
\hline \multirow{2}{*}{$\begin{array}{c}\text { Degree of } \\
\text { pain }\end{array}$} & 3 D GIS & OH & P value \\
\cline { 2 - 3 } & NO (\%) & NO (\%) & \\
\hline NO & $23(12.8)$ & $23(12.8)$ & \multirow{2}{*}{$0.001 * *$} \\
\hline Mild & $119(66.1)$ & $119(66.1)$ & \multirow{2}{*}{ \% } \\
\hline Moderate & $27(15.0)$ & $27(15.0)$ & \\
\hline Severe & $11(6.1)$ & $11(6.1)$ & \\
\hline
\end{tabular}

**highly significant

Table3. Comparison between $3 \mathrm{D}$ GIS and $\boldsymbol{O} \boldsymbol{H}$ as regard to complications related to procedures

\begin{tabular}{|c|c|c|c|}
\hline & 3 D GIS & OH & \multirow{2}{*}{ P value } \\
\cline { 2 - 3 } & No. $(\boldsymbol{\%})$ & No. $(\%)$ & \\
\hline Headache & $2(1.1)$ & $18(10.0)$ & $<0.01 * *$ \\
\hline $\begin{array}{c}\text { Allergic } \\
\text { reactions }\end{array}$ & $3(1.7)$ & $2(1.1)$ & $>0.05$ \\
\hline vomiting & $2(1.1)$ & $3(1.7)$ & $>0.05$ \\
\hline Bleeding & $\begin{array}{c}27 \\
(15.0)\end{array}$ & $70(38.9)$ & $<0.05^{*}$ \\
\hline
\end{tabular}

*mild significance **moderate significance

Table 4 shows uterine cavity abnormalities for both procedures, no statistically significant difference was present between both procedures.

Table4. Uterine cavity abnormalities diagnosed by 3 $D$ GIS and $\mathrm{OH}$

\begin{tabular}{|c|c|c|c|}
\hline & 3 D GIS & OH & \multirow{2}{*}{ P value } \\
\cline { 2 - 3 } & No. (\%) & No. (\%) & \\
\hline Abnormal & $27(15 \%)$ & $27(15 \%)$ & $>0.05$ \\
\hline Normal & $\begin{array}{c}153 \\
(85 \%)\end{array}$ & $\begin{array}{c}153 \\
(85 \%)\end{array}$ & \\
\hline Total & 180 & 180 & - \\
\hline
\end{tabular}

Table5 and 6 show sensitivity, specificity, negative and positive predictive values for $3 \mathrm{D}$ GIS

Table5. Sensitivity, specificity, positive and negative predictive values of $3 D$ GIS

\begin{tabular}{|l|l|l|l|l|}
\hline Sensitivity & Specificity & +ve PP & -ve PP & Accuracy \\
\hline $24 / 27$ & $150 / 153$ & $24 / 27$ & $150 / 153$ & $(96.7 \%)$ \\
$(88.9 \%)$ & $(98 \%)$ & $(88.9 \%)$ & $(98 \%)$ & \\
\hline
\end{tabular}

Table6. Sensitivity, specificity, negative and positive predictive values for $3 D$ GIS in diagnosing uterine cavity lesions

\begin{tabular}{|c|c|c|c|c|c|}
\hline & Sensitivity & Specificity & +ve PP & -ve PP & Accuracy \\
\hline Endometrial polyp & $15 / 17(88.2 \%)$ & $160 / 163(98.1 \%)$ & $15 / 18(83.3 \%)$ & $160 / 162(98.7 \%)$ & $97.2 \%$ \\
\hline Submucous fibroid & $3 / 3(100 \%)$ & $177 / 177(100 \%)$ & $3 / 3(100 \%)$ & $177 / 177(100 \%)$ & $100 \%$ \\
\hline $\begin{array}{c}\text { Septate uterus } \\
\begin{array}{c}\text { Intrauterine } \\
\text { adhesions }\end{array}\end{array}$ & $3 / 3(100 \%)$ & $177 / 177(100 \%)$ & $3 / 3(100 \%)$ & $177 / 177(100 \%)$ & $100 \%$ \\
\hline Biconuate uterus & $1 / 1(100 \%)$ & $177 / 177(100 \%)$ & $2 / 2(100 \%)$ & $177 / 178(99.4 \%)$ & $99.4 \%$ \\
\hline
\end{tabular}

\section{DISCUSSION}

Uterine factor represents only 2 to $3 \%$ of female infertility, but intrauterine lesions are more common in this condition (40-50\%). These lesions can affect the natural fertility beside affect pregnancy rates [21, 22]. Acquired uterine lesions, such as uterine fibroids, endometrial polyps, intrauterine adhesions, or all of these, may cause infertility by interfering with proper embryo implantation and growth [3]. Gel instillation can be used as an alternative for saline infusion during sonohysterography. The technique is easy to learn and seems attractive as a first choice because the technique is convenient for both the patient and the ultrasonographer. GIS offers a more stable filling of the uterine cavity, which allows detailed examination with a very precise visualization of the uterine cavity and its linings. The use of gel for this purpose is not entirely new; a dextran 70 solution was described in 1987 in first study on ultrasound and uterine cavity distension [23].

In our study, 180 patients with suspected uterine factor of infertility or a cause for recurrent pregnancy wastage were included. Patients suffered from 1ry infertility were $60.5 \%, 31.7 \%$ had 2ry infertility and $7.8 \%$ suffered from recurrent pregnancy loss (Table 1).

As regard to pain related to procedures according to pain score, patients experience discomfort or pain sensation with 3D GIS were lesser than $\mathrm{OH}$ so GIS was well tolerated and accepted by the patients (Table 2), these results were agreed with what was reported by (Van Den Bosch et al., 2009) [24].

As regards to complications experienced by patients during both procedures, complications were more obvious in $\mathrm{OH}$ particularly post procedure headache and bleeding (Table 3).

for 3D GIS, sensitivity, specificity, positive and negatice predictive values were $88.9 \%$, 
98\%, $88.9 \%$ and $98 \%$ respectively (Table 5), these findings were comparable to findings of Yahia and Ahmed, (2015) who reported in their study that the overall sensitivity of GIS was $81 \%$ specificity $97.5 \%$, positive predictive value $90 \%$ and negative predictive value $94 \%$ ) [11]. Sensitivity and negative predictive value of 3D GIS in our study were higher than what was reported by Erika et al., $2011(85.0 \%$ and $88.6 \%$ ) respectively [25].

As regard to diagnostic value of 3D GIS in uterine cavity anomalies and intrauterine lesions, we found that 3D GIS had high sensitivity and specificity (100\%) for mullerian duct anomalies and submucous fibroid but had the lowest specificity for intrauterine adhesions detection $(66.7 \%)$ on the other hand positive predictive value was $100 \%$ for mullerian duct anomalies, submucous fibroid and intrauterine adhesions but 88.9 for intrauterine polyps (table 6). Negative predictive value of 3D GIS had high values for detection of uterine cavity anomalies and intrauterine lesions, these results is in agreement with what had been reported by Emanuel et al., 2009 who reported high accuracy of GIS in diagnosis of pedunculated polyp, sessile polyp, pedunculated myoma (89\%) [26].

In our study the 3D GIS had high sensitivity, specificity, positive and negative predictive values in comparison to other studies in uterine cavity assessment so 3D GIS can be used as an alternative method for assessment of intrauterine lesions or presence of any congenital anomalies in the uterine cavity in infertility work up particularly in those under preparation for ICSI procedures because it safer, cheaper, noninvasive in comparison to hysteroscopy and can assess all other pelvic structures. $3 \mathrm{D} \mathrm{TV}$ $\mathrm{U} / \mathrm{S}$ in coronal section can detect any abnormalities in mullarian duct fusion as biconuate uterus and uterine septum also $3 \mathrm{D}$ TV U/S can measure endometrial volume and detect sub endometrial zone and assess uterine and ovarian blood velocity using Doppler u/s. The advantage of GIS over SIS that gel has slow uterine cavity filling and remains in cavity for a while that give chance for precise detection of any abnormalities or pathological lesion besides it is seldom pass from Ostia because of its high viscosity so no fear of any rarely allergic or inflammatory reaction in peritoneal cavity.

\section{CONClusions}

Uterine cavity assessment is mandatory prior to ICSI procedure. $3 \mathrm{D}$ GIS had high sensitivity, specificity, positive and negative predictive values in detecting uterine cavity abnormalities comparable to $\mathrm{OH}$. It is characterized by higher safety, lower cost, minimal invasion method with no need for anesthesia or analgesia and can be applied without special preparations in comparison to $\mathrm{OH}$.

\section{RECOMMENDATIONS}

$3 \mathrm{D}$ GIS is to be used as an alternative to office hysteroscopy in uterine cavity assessment in patients with reproductive failure prepared for ICSI procedure.

\section{REFERENCES}

[1] Pansky M, Feingold M, Sagi R, Herman A, Schneider D, Halperin R:Diagnostic Hysteroscopy as a Primary Tool in a Basic Infertility Workup. Journal of the Society of Laparoendoscopic Surgeons (2006)10:231-235.

[2] Linderman H, Mohr J. CO2 hysterosocpy, diagnosis and treatment. Am. J Obstet Gynecol 1976; 124:129-133.

[3] Brown SE, Coddingion CC, Schnorr J, Toner J, Gibbons W, Oehninger S. Evaluation of outpatient hysteroscopy, saline infusion hysterosonography and hysterosalpingiography in infertile women. A prospective randomized study. Fertil steril 2000; 74:1029-34.

[4] Mooney SB, Milki AA. Effect of hysteroscopy performed in the cycle preceding controlled ovarian hyperstimulation on the outcome of in vitro fertilization. Fertil steril, 2003;79:637-8

[5] Koskas M, Mergui JL, Yazbeck C, Uzan S, Nizard J. Office hysteroscopy for infertility: a series of 557 consecutive cases. Obstet Gynecol Int .2010; 2010:168096.

[6] Sylvestre C, Child TJ, Tulandi T, Tan SL. A prospective study to evaluate the efficacy of two- and threedimensional sonohysterography in women with intrauterine lesions. Fertil Steril. 2003; 79:1222-25.

[7] De Placido G, Clarizia R, Cadente C, Castaldo G, Romano C, Mollo A, Alviggi C, Conforti S. Compliance and diagnostic efficacy of minihysteroscopy versus traditional hysteroscopy in infertility investigation. Eur. J. Obstet. Gynecol. Reprod. Biol. 2007; 135:83-87.

[8] Hamilton JA, Larson AJ, Lower AM, Hasnain S, Grudzinskas JG. Routine use of saline hysterosonography in 500 consecutive, unselected, infertile women. Hum Reprod 1998; 13:2463-73.

[9] La Sala GB, Blasi I, Gallinelli A, Debbi C, Lopopolo G, Vinci V, et al. Diagnostic accuracy of sonohysterography and transvaginal sonography as compared with hysteroscopy and endometrial biopsy: a prospective study. Minerva Ginecol.2011; 639(5):421-7. 
[10] Bartkowiak R, Kaminski P, Wielgos M, Bobrowska K. The evaluation of uterine cavity with saline infusion sonohysterography and hysteroscopy in infertile patients. Neuro Endocrinol Lett.2006; 27:523-8.

[11] Yahia El-Faissal and Ahmed El lithy Middle East Fertility Society Journal Volume 20, Issue 1, March 2015, Pages 6-10.

[12] Lotte L. Nieuwenhuis a, Marjolein A.J. Bij de Vaate a, Wouter J.K. Hehenkamp a, Martijn W. Heymans, Marchien W.M. van Baal c, Hans A.M. Brölmann a, 6 Judith A.F. Huirne) European Journal of Obstetrics \& Gynecology and Reproductive Biology (2014 -8576 1-6)

[13] Exalto, N., Stappers, C., van Raamsdonk, L.A.M., Emanuel, M.H., 2007. Gel instillation sonohysterography: first experience with a new technique. Fertil. Steril. 87, 152-155.

[14] Goldstein, S.R., 2010. Modern evaluation of the endometrium. Obstet. Gynecol. 116, 168-176

[15] Bij de Vaate, A.M.J., Brölmann, H.A.M., van der Slikke, J.W., Emanuel, M.H., Huirne, J.A.F., 2010. Gel instillation sonohysterography (GIS) and saline contrast sonohysterography (SCSH): comparison of two diagnostic techniques. Ultrasound Obstet. Gynecol. 35, 486-489.

[16] Rijksen, I., Spaans, W.A., 2009. GIS: een bijna fatale vergissing? Ned. Tijdschr. Obetet. Gynaecol. $122,138-140$.

[17] Emanuel, M.H., Exalto, N., 2011. Hysterosalpingofoam sonography (HyFoSy): a new technique to visualize tubal patency. Ultrasound Obstet. Gynecol. 37, 497-499.

[18] Emanuel, M.H., van Vliet, M., Weber, M., Exalto, N., 2012. First experiences with hysterosalpingofoam sonography (HyFoSy) for office tubal patency testing. Hum. Reprod. 27, 114-117.

[19] Van Schoubroeck, D., Van den Bosch, T., Meuleman, C., Tomassetti, C., D'Hooghe, T.,
Timmerman, D., 2013. The use of new gel foam for the evaluation of tubal patency. Gynecol. Obstet. Invest. 75, 152-156

[20] Visual Analog Scale and Verbal Pain Intensity Scale: From Pain Management: Theory and Practice, edited by RK Portenoy \& RM Tanner, copyright 1996 by Oxford University Press, Inc.

[21] Bosteels J, Kasius J, Weyers S, Broekmans FJ, Mol BWJ, D'Hooghe TM. Hysteroscopy for treating subfertility associated with suspected major uterine cavity abnormalities. Cochrane Database of Systematic Reviews. 2013; (1) CD009461 [PubMed]

[22] Taylor E, Gomel V. The uterus and fertility. Fertility and Sterility. 2008; 89(1):116. [PubMed]

[23] van Roessel J, Wamsteker K, Exalto N. Sonographic investigation of the uterus during artificial uterine cavity distention. J Clin Ultrasound 1987; 15: $439-50$.

[24] T. Van Den Bosch, G. Betsas, D. Van Schoubroeck, A. Daemen, V. Vandenbroucke, A. Cornelis, B. De Moor, J. Deprest and D. Timmerman: Gel infusion sonography in the evaluation of the uterine cavity. Ultrasound Obstet Gynecol 2009; 34: 711-714.

[25] Erika Werbrouck, Joan Veldman, Jan Luts, Sabine Van Huffel, Dominique Van Schoubroeck, Dirk Timmerman, Thierry Van den Bosch: Detection of endometrial pathology using saline infusion sonography versus gel instillation sonography: a prospective cohort study. Fertility and Sterility Volume 95, Issue 1, January 2011, Pages 285-288.

[26] Emanuel M. H., Tromp I., Betlem M : The diagnostic accuracy of gel instillation sonohysterography (GIS) compared with saline infusion sonohysterography (SIS); a randomised controlled trial. Ultra sound in obstetrics and gynecology. September 2009; Volume 34, Page 20.

Citation: Abd El Naser Abd El Gaber Ali, Ahmed Ali M. Nasr, Hazem H. Ahmed, Mostafa M. Khodry, Mahmoud I. El-Rasheedy. Uterine Cavity Assessment Prior to ICSI in Patients with Reproductive Failure: 3 Dimensional Gel Instillation Sonohysterography VS. Office Hysteroscopy. ARC Journal of Gynecology and Obstetrics 2017; 2(4):5-10. DOI: dx.doi.org/10.20431/2455-9792.0204002

Copyright: (c) 2017 Authors. This is an open-access article distributed under the terms of the Creative Commons Attribution License, which permits unrestricted use, distribution, and reproduction in any medium, provided the original author and source are credited. 